\title{
FRESHWATER ARTIFICIAL REEFS AS A WAY TO INCREASE OF THE PRODUCTIVITY
}

\author{
T. L. Kalita (a)*, O. N. Mingaleova (b), D. S. Khatuntsov (c), A. N. Zhavnerov (d) \\ *Corresponding author
}

(a) K.G. Razumovsky Moscow State University of Technologies and Management (the First Cossack University), 73, Zemlyanoy Val str., Moscow, Russia, t.kalita@mgutm.ru

(b) K.G. Razumovsky Moscow State University of Technologies and Management (the First Cossack University), 73, Zemlyanoy Val str., Moscow, Russia, olchijj@mail.ru

(c) K.G. Razumovsky Moscow State University of Technologies and Management (the First Cossack University), 73, Zemlyanoy Val str., Moscow, Russia,wanohka@gmail.com

(d) K.G. Razumovsky Moscow State University of Technologies and Management (the First Cossack University), 73, Zemlyanoy Val str., Moscow, Russia, a.zhavnerov@mgutm.ru

\begin{abstract}
Artificial reefs are man-made or natural objects located, as a rule, at the bottom of the coastal zone of the seas. The creation of artificial reefs is considered not only an adequate ecological measure, but also the most effective and economical means for increasing the productivity and cleaning of water bodies. However, freshwater artificial reefs are currently practically undeveloped, so the purpose of the work was to collect all information about the materials, location and use of freshwater reefs and to give recommendations on the design of reefs for rivers. Currently, artificial reefs are successfully used to increase productivity and purify water in freshwater bodies, mainly in lakes and reservoirs. The use of reefs in rivers is not known and requires further research. The most promising reef models are Reef Bols, Ecotangres and combined structures of ceramic pipes, branches and concrete blocks. Testing of such structures of artificial reefs in the area of whirlpools and river reaches as a biofilter is the goal of our further research.
\end{abstract}

2672-8575 (C) 2022 Published by European Publisher.

Keywords: Artificial reefs, freshwater, Reef Ball, soft barriers 


\section{Introduction}

The exploitation of natural resources in river basins leads to depletion and pollution of water resources. In the basins of small rivers, a similar process manifests itself in a more pronounced form. As a rule, anthropogenic impact is manifested in the rapid accumulation of a large amount of dead organic matter and silt at the bottom of fresh water bodies, which contributes to the powerful development of the decomposers community. At the same time, the reservoir loses its attractiveness as a recreational area. For the natural removal of excess nutrients, a powerful development of benthic and nekton communities is necessary, and, first of all, filter feeders and sedimentators. In addition, the species diversity of all other benthic forms should be increased, since the higher the diversity, the faster the restoration of hydrobiocenoses occurs (Alimov, 2000). The species diversity in such water bodies depends on the availability of solid substrates for the attachment of phyto- and zoobenthos, and the creation of shelters for nekton organisms. The benthos of solid soils not only actively absorbs organic matter, but also feeds nekton organisms, which ultimately increases the productivity of water bodies.

\section{Problem Statement}

Artificial reefs are man-made or natural objects, usually located at the bottom of the coastal zone of the seas (Parker et al., 1974) Creation of artificial reefs is considered not only an adequate ecological measure, but also the most effective and economical means. However, freshwater artificial reefs are currently largely undeveloped. The purpose of this report is to summarize information on freshwater reef: the materials, location and using; and to provide recommendations for the design of reefs for rivers.

\section{Research Methods}

\subsection{Reef types and their meaning}

Solid anthropogenic substrates are divided into several groups: random (for example, sunken ships), secondary (communities of overgrowing anthropogenic substrates - oil platforms, ships, piers, breakwaters, artificial islands, etc.) and artificial reefs (Bukina, 2017).

An artificial reef is a submerged or drifting solid object, the purpose of which is to imitate the functions of a natural reef: protection, reproduction and concentration of benthic and nekton organisms (Fabi et al., 2015; Bukina, 2017). Thanks to it, it is possible to purposefully influence the qualitative and quantitative composition of aquatic organisms in a given place of the reservoir (Pupyshev, 1988). Most often, artificial reefs are installed to improve the efficiency of coastal fisheries (Zaitsev, 1987). In Russia, the creation of reefs is focused on increasing the productivity of marine areas and the creation of active biofilters in contaminated areas (Bukina, 2017). We suggest using artificial reefs as a biofilter in fresh water.

Hubbs (1930) was one of the first scientists to use artificial reefs to improve the efficiency of coastal fisheries in the lake. Michigan. He noted that artificial reefs concentrate a large number of fish around them. Subsequent studies have shown that in the stagnant waters of lakes and reservoirs in the area of artificial reefs, such fish as perch (bass), catfish (catfish), sunfish (sunfish) concentrate and spawn, 
while in shallow water, small individuals are the most numerous, and at depth 4-6 $\mathrm{m}$ the largest are found; phyto- and zoobenthos settle on the surface of reefs, increasing the biological productivity of water bodies (Prince, 1976; Prince et al., 1977). However, it was noted that in the temperate zone at a depth of $6 \mathrm{~m}$ and less in winter, fish are practically not found (Prince, 1976).

In Russia, artificial freshwater reefs are placed mainly in the water area of lakes and reservoirs. So, in 2012, a line of 15 reefs was established perpendicular to the coast at the bottom of the Vazuz reservoir. Each reef consisted of three mutually perpendicular expanded clay concrete beams $1550 \mathrm{~mm}$ long. It was shown that there are significant accumulations of fish near the reef, while the catch was 1.6-1.8 times higher in the number of individuals and 1.5-2.25 times in mass (Kuznetsov et al., 2015).

\subsection{Installation method}

According to the method of installation, artificial reefs are divided into three groups: bottom, floating on the surface and in the water column. Currently, preference is given to bottom artificial reefs.

As floating artificial reefs in fresh water bodies, it is possible to use floating breakwaters to concentrate pelagic species in one place (Hammond et al., 1977).

When building artificial reefs, it is very important to correctly determine the location of the reef. Successful results will be influenced by the bottom topography, water hydrodynamics, the state of the microfauna, and anthropogenic load (Okamoto et al., 1979).

\subsection{Artificial reef materials}

The materials most commonly used to build artificial reefs can often cause pollution by releasing chemicals not found in the natural environment. For example, ships that have sunk can emit polychlorinated biphenyls (PCBs), asbestos, iron, lead paint, and paint tends to wash out in water bodies, after which it can enter the food chain (Jacobson, 2016).

Until recently, old tires were often used to create artificial reefs (figure 1A), as early as the 70 s. of the last century, it was shown that in water, old tires absorb dissolved mercury from wastewater (Bushnell, 1976), while not emitting toxic substances (Nozaka et al., 1973; Stone et al., 1974). Tire reefs were actively inhabited by aquatic organisms, especially in temperate latitudes, for example, in the Sea of Azov near the reef, a 42 -fold increase in the number of round gobies was noted; on the tire surface, a powerful community of filter feeders of mussels, balanus, and oysters was formed (Yanovsky, 1987). In the Amur Bay, artificial reefs created local currents around them, which eroded liquid silts, as a result of which the biologically productive zone was constantly expanding (Bukina, 2017). However, the benefits of using old tires as reefs are currently questionable. Firstly, during the decomposition of tires, harmful substances such as zinc, copper, oil products, formaldehyde and acetone are released (Bukina, 2017). Secondly, during storms, relatively light tires are thrown ashore, while they mechanically manage to destroy natural benthic communities, this process is especially dangerous for coral reefs. Therefore, now a powerful volunteer movement is connected to cleaning tires from the bottom of reservoirs. In addition, in order to improve the state of hydrobiocenoses, artificial bottom landscapes are now being created, in the creation of which various public organizations are involved. For example, in Russia such a public 
organization is the Artificial Reefs, a non-profit charitable foundation for the development of underwater environmental programs, created by Sergei Fedotov (http://www.artificialreefs.ru).

The best material for reefs is porous concrete blocks (Brock \& Norris, 1989), which are composed of environmentally friendly materials: $40 \%$ cement, $25 \%$ crushed stone, $20 \%$ sand and $15 \%$ water. Tests have shown that reefs made of such concrete are durable, do not negatively affect the environment, and an abundant community of filter feeding aquatic organisms forms on their surface (Collins et al., 1991; Sampaolo \& Relini, 1991; Shien \& Duedal, 1991). Also, artificial reefs can be formed from ceramic pipes, concrete blocks with numerous holes, hammered into the bottom of concrete or wooden solid or prefabricated posts, numerous brushes made of branches or plastic. The choice of the design and material of the reef for fresh water bodies is a rather complicated process and strongly depends on the type of water body and its size (lake, reservoir, river). For example, Swingle (1968) found that the use of brush structures in a lake improved the plumpness of sun fish, but did not increase the number of stunted fish.

For fresh water bodies, artificial reefs in the form of brushes (figure 1B) are widely used, which are made from freshly cut branches of oak, conifers (Prince et al., 1977), or plastic (Prazukin et al., 2016). It is possible to combine clay pipes, concrete blocks with bunches of branches. Stakes up to $2 \mathrm{~m}$ long are also used, which are driven into the bottom of the lake in winter on an area of $1.2 \mathrm{~m}$ by $2.5 \mathrm{~m}$; A type of such a reef is the strengthening of stakes on a wooden frame, which is then moved to the desired place and flooded with concrete blocks. In Russia EcoTangr is a promising method for creating underwater habitats of aquatic organisms, filtration fields, and diving parks in Russia (figure 1C). EcoTangres are special metal rods driven into the bottom of reservoirs at a distance of 10-50 cm from each other. They are actively overgrown with algae, filter feeding animals. Such reefs were tested on the sandy bottom of the Black Sea by specialists from the Artificial Reefs Nonprofit Charitable Foundation (http://www.artificialreefs.ru/1/ecotangr/).

The most promising construction of an artificial reef in offshore areas is currently considered to be the "Reef ball" (figure 1D). Reef balls simulate boulders on the seabed with a large number of holes and internal cavities in which mobile organisms find shelter and shelter. The surface of the "Reef ball" is actively populated by benthic filter-feeding organisms. So, $1 \mathrm{~m}^{2}$ of mussel colonies is able to filter from 7 to $20 \mathrm{~m}^{3}$ of water. Made of special concrete, "Reef balls" are designed for a service life of 500 years or more (International Movement "Artificial Reefs", 2005). The application of technologies "Reef ball" and "Ecotangr" in fresh water bodies has not been described, but in our opinion, it is promising

\subsection{Size and number of reefs}

The size and number of reefs should be commensurate with the size of the freshwater body. Wilbur et al. (1973) note that the artificial reef area should not exceed $0.25 \%$ of the lake's surface area, i.e., 0.1 hectares of reef per 40 hectares of lake and this area may contain no more than three reefs. Therefore, some studies suggest the creation of reefs in stages until the size of the reefs is sufficient to maintain fisheries at the required level (Prince et al., 1977). In addition, reefs should be positioned perpendicular to the coast from shallow water $(1.5 \mathrm{~m})$ to maximum depth (over $6 \mathrm{~m})$, as some species change their preferred temperature throughout the year (Prince, 1976). 


\section{Conclusion}

Thus, artificial reefs are successfully used to increase productivity and purify water in freshwater bodies, mainly in lakes and reservoirs. The use of reefs in rivers is not known and requires further research. The most promising reef models are "Reef ball", "EcoTangry" and combined structures of ceramic pipes, branches and concrete blocks.

A
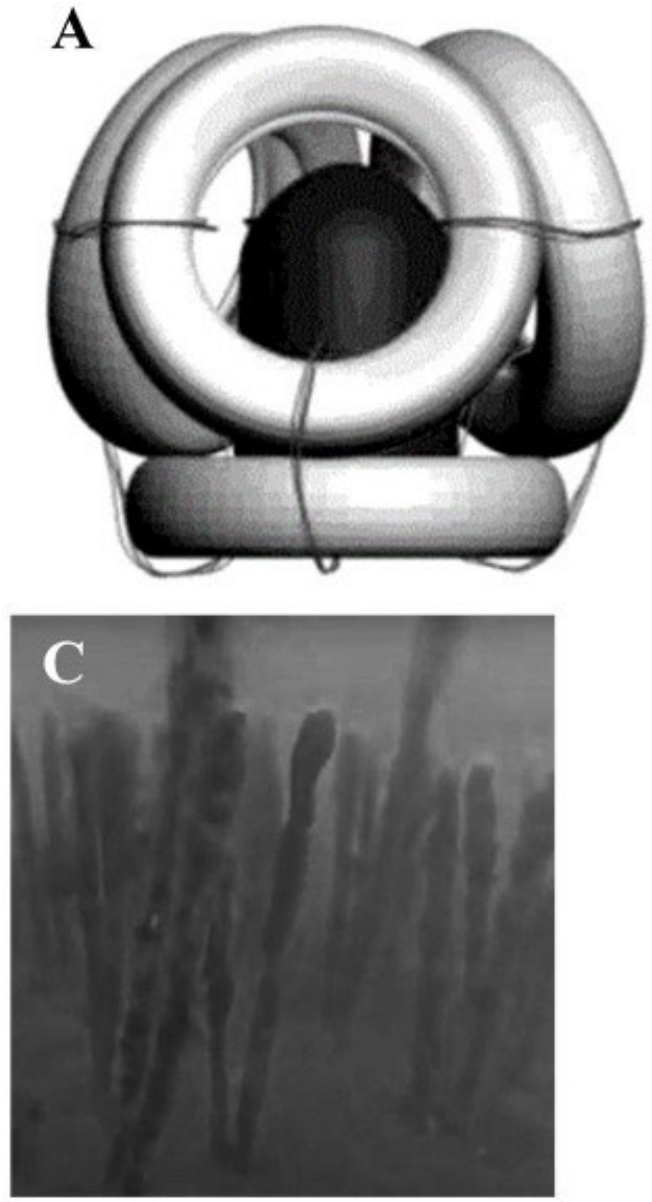

B

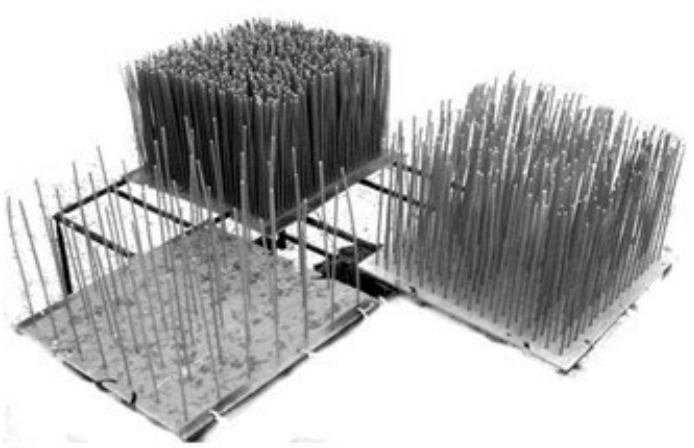

D

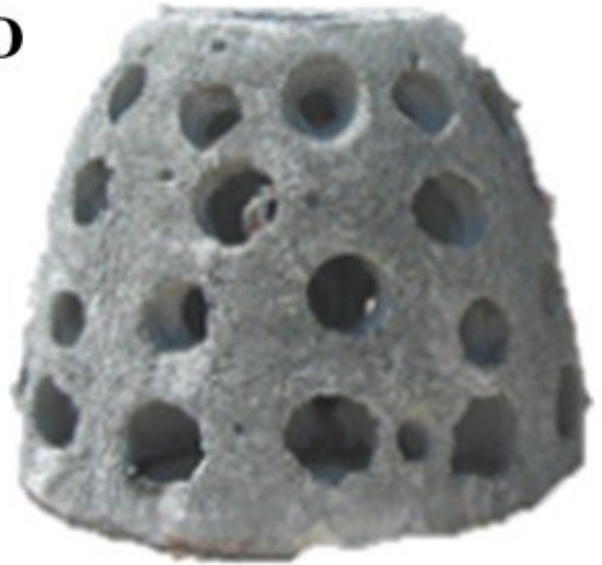

Figure 1. Types of artificial reefs. (A) from tires, Gireyeva et al., 2009, (B) in the form of brushes, Prazukin et al., 2016; (C) EcoTangry and (D) Reef ball, http://www.artificialreefs.ru/1/reefball.html

Testing of such constructions of artificial reefs in the area of whirlpools and river reaches is the goal of our further research. In addition, when designing artificial reefs, remember that 1) the reef must be worth the time, labor, and installation costs, and 2) durable building material extends the life of the reef and reduces the proportionate cost of making it. 


\section{References}

Alimov, A. F. (2000). Elements of the functioning of aquatic ecosystems. Science.

Brock, R. E., \& Norris, J. E. (1989). An analysis of the efficacy of four artificial reef designs in tropical water. Bull. Mar. Sci., 44(2), 757-766.

Bukina, Y. A. (2017). Analysis of the effectiveness of the installation of artificial reefs in the seas of the Russian Federation. Science and Modernity - a collection of materials from the LI International Scientific and Practical Conference (pp. 221-225). Novosibirsk: Limited Liability Company "Center for the Development of Scientific Cooperation".

Bushnell, G. (1976). Pollution solution. Sports Afield, 175(1), 89.

Collins, K. J., Jensen, A. C., \& Lockwood, A. P. M. (1991). Artificial reefs: Using coal-fired power station wastes constructively for fishery enhancement. Oceanologica Acta, 11, 225-229.

Fabi, G., Scarcella, G., Spagnolo, A., Bortone, S. A., Charbonnel, E., Goutayer, J. J., Haddad, N., Lök, A., \& Trommelen, M. (2015). Practical guidelines for the use of artificial reefs in the Mediterranean and the Black Sea. General Fisheries Commission for the Mediterranean, 96, 1-74.

Gireyeva, E. S., Novikova, Y. A., \& Semenenko, V. I. (2009). Biotechnical substantiation of the use of sanitary mariculture for cleaning water areas from industrial and domestic discharges. Scientific works of Dalrybvtuz, 21, 6.

Hammond, D. L., Myatt, D. O., \& Cupka, D. M. (1977). Evaluation of midwater structures as a potential tool in the management of the fisheries resources of South Carolina's artificial fishing reefs. South Carolina Marine Resources Center, Technical Report Series, 15, 19.

Hubbs, C. L. (1930). Fishery research in Michigan. Transactions of the American Fisheries Society, 60(1), 182-186. https://doi.org/10.1577/1548-8659(1930)60[182:FRIM]2.0.CO;2

International Movement "Artificial Reefs". (2005). www.ArtificialReefs.ru

Jacobson, L. (2016). Artificial Reefs, Sunken Ships, and Military Toxins. http://www.toxipedia.org/display/toxipedia/Artificial+Reefs,+Sunken+Ships,+and+Military+Toxi ns

Kuznetsov, V. V., Kuznetsova, E. N., Goncharov, S. M., Popov, S. B., Belorustseva, S. A., \& Mititello, A. V. (2015). Assessment of the impact of an artificial reef on the freshwater community of aquatic organisms. Aquatic biological resources, 155, 69-78.

Nozaka, H., Nagago, Y., \& Kikuchi, M. (1973). Tire fish reef. Ocean Age (in Japanese).

Okamoto, M., Kuroki, T., \& Mural, T. (1979). Fundamental studies on the ecology of fishes near artificial reefs: I. Preparatory observations of fish amount II Bull. Jap. Soc. Fish, 45(9), 1085-1090. https://doi.org/10.2331/suisan.45.1085

Parker, R. O., Stone, R. B., Buchanan, C. C., \& Steimle, F. W. Jr. (1974). How to build marine artificial reefs. https://digitalcommons.unl.edu/cgi/viewcontent.cgi?article=1208\&context=usdept commercepub

Prazukin, A. V., Firsov, Y. K., Kholodov, V. V., \& Lee, R. I. (2016). Seasonal dynamics of biofouling of artificial reef structures in the eutrophied sea area. Marine biological research: achievements and prospects: in 3 volumes: collection of articles. materials Vseros. scientific-practical conf. with int. participation, timed. to the 145th anniversary of the Sevastopol Biological Station (Sevastopol, September 19-24, 2016). T. 3., 432-435. Sevastopol: InBYUM.

Prince, E. D. (1976). Biological effects of artificial tire reefs in Smith Mountain Lake, VA. Blacksburg.

Prince, E. D., Maughan, O. E., \& Brouha, P. (1977). How to build a freshwater artificial reef. Virginia Polytechnic Institute and State University.

Pupyshev, V. A. (1988). Artificial reefs. Fish industry, 6, 68.

Sampaolo, A., \& Relini, G. (1991). Coal ash for artificial habitats in Italy. Fifth international conference for aquatic habitat enhancement, 3-7. Long Beach, California.

Shien, C. S., \& Duedal, I. W. (1991). Chemical properties and behavior of a stabilized oil ash reed located off the east coast of Florida, US. Fifth international conference for aquatic habitat enhancement, Long Beach, California. 
Stone, R. B., Buchanan, C. C., \& Steimle, G. W. Jr. (1974). Scrap tires as artificial reefs. U.S. Environmental Protection Agency.

Swingle, H. S. (1968). Biological means of increasing productivity in ponds. FAO Fish. Rep, 44(4), 243257.

Wilbur, R. L., May, B. E., \& Lansford, F. H. (1973). Habitat manipulation. Florida Game and Freshwater Fish Commission, Dingell-Johnson Project F-26, Annual Progress Report. 300.

Yanovsky, E. G. (1987). The use of artificial reefs to increase the fish productivity of the Sea of Azov. Collection of scientific works of VNIRO (pp. 90-92). VNIRO.

Zaitsev, Y. P. (1987). Artificial reefs are a tool for managing ecological processes in the coastal zone of the sea. Artificial reefs for fisheries. Abstracts. report All-Union. conf. (Moscow, December 2-4, 1987). Moscow. 